\title{
STUDIES ON A VIRUS FROM A PATIENT WITH FORT BRAGG FEVER (PRETIBIAL FEVER)
}

\author{
By HUGH TATLOCK 1 \\ (From the Respiratory Disease Commission Laboratory, ${ }^{2}$ Regional Station Hospital, Section 2, \\ Fort Bragg, North Carolina; the Division of Virus and Rickettsial Diseases, Army \\ Medical School, Washington 12, D. C.; the Children's Hospital Research \\ Foundation and Department of Pediatrics, University of \\ Cincinnati College of Medicine, Cincinnati 29, Ohio ${ }^{3}$ )
}

(Received for publication October 8, 1946)

During the summer of 1942, an outbreak of a dengue-like illness of unknown etiology occurred at Fort Bragg, North Carolina. The disease, described by Daniels and Grennan (1), was characterized by moderate prostration, fever, splenomegaly, a rash localizing particularly on the anterior aspects of the legs, and a short course. The localization of the rash gave rise to the name "pretibial fever." Epidemiological information indicated that all of the patients in this outbreak were quartered in the same area of the post and that the incubation period was 10 days or longer. Serological tests served to exclude endemic typhus, infectious mononucleosis, brucellosis, and the typhoid-paratyphoid group of diseases. A commission was assigned by the Surgeon General of the United States Army to investigate the epidemiology and etiology of the disease. Working with frozen material in the form of blood, nasal washings, and urine from the patients, the members of the commission concluded: "All tests on this material proved negative as far as isolating or

1 Captain, MC, AUS. Part of this work was done by the author while serving as a member of the Commission on Acute Respiratory Diseases and part while Chief of the Communicable Disease Section, Walter Reed General Hospital, Army Medical Center, Washington, D. C.

2 Work done at Fort Bragg, North Carolina, was supported in part through the Commission on Acute Respiratory Diseases, Army Epidemiological Board, Preventive Medicine Service, Office of the Surgeon General, United States Army, and by grants from the Commonwealth Fund, the W. K. Kellogg Foundation, the John and Mary R. Markle Foundation, and the International Health Division of the Rockefeller Foundation to the Army Epidemiological Board for the Commission on Acute Respiratory Diseases.

8 The studies in Cincinnati were supported by the Commission on Neurotropic Virus Diseases, Army Epidemiological Board, Preventive Medicine Service, Office of the Surgeon General, U. S. Army. determining the nature of the infectious agent responsible for this disease was concerned" (2).

Similar outbreaks appeared during the summers of 1943 and 1944. The present report describes the recovery of an infectious agent from a patient having Fort Bragg fever in 1944 and summarizes observations on the biological characteristics of this agent. In addition, it presents the results of neutralization tests which indicate that the agent is related to the human infection; and finally, it describes the reproduction of the clinical disease picture in human subjects inoculated with the agent.

\section{PART I}

\section{RECOVERY OF A VIRUS AND ITS CHARACTERISTICS}

\section{Recovery of the agent from a patient}

On August 16, 1944, a 22-year-old white soldier noted a sudden onset of headache, feverishness, and generalized aching. In spite of these symptoms, he continued on duty until August 19 when his symptoms increased following a stimulating injection of tetanus toxoid, and he was hospitalized. Physical examination showed an acutely ill patient with a fever of $102^{\circ} \mathrm{F}$., whose only other abnormal physical finding was a questionably palpable spleen. The leukocyte count was 5,750 per cubic $\mathrm{mm}$. An indistinct maculopapular eruption was noted over the pretibial areas on August 21. This rash faded after 2 days. During his illness the patient showed a remittent temperature which reached $103^{\circ}$ to $104.5^{\circ} \mathrm{F}$. for 5 days. A blood culture taken shortly after the appearance of the rash proved sterile. Two days after defervescence he was completely recovered and was discharged from the hospital. The clinical diagnosis was Fort Bragg Fever.

Two Syrian hamsters and two guinea pigs were injected intraperitoneally with blood freshly drawn from this patient on August 21, 1944, 5 days after onset, when his temperature was $104.5^{\circ} \mathrm{F}$. Both hamsters were found dead on the tenth day. No macroscopic abnormalities were found at autopsy and the viscera were bacteriologically sterile. Passage to other hamsters was 
not attempted. Both guinea pigs developed fever $\left(105^{\circ}-\right.$ $106^{\circ}$ F.) 8 days after inoculation. On the second day of fever, one of the animals was sacrificed; citrated blood, suspensions of brain, pooled liver and spleen, and tunica vaginalis were obtained and each injected into two guinea pigs by the intraperitoneal route. Cultures of the blood and organs of the guinea pig showed no growth. After a 7-day incubation period, fever developed in guinea pigs of the groups which had received blood and pooled liver and spleen; but no disease appeared in the other animals. A febrile illness was regularly induced in passage animals inoculated with citrated blood from affected guinea pigs. A similar febrile illness was induced and maintained by passage in guinea pigs injected with suspensions of liver and spleen of such animals; after the fourth serial passage, this line was abandoned for convenience. The stock colonies of the guinea pigs and hamsters were free from intercurrent disease at the time, as evidenced by several negative experiments employing intraperitoneal injections of blood from patients with other diseases.

\section{Pathogenicity for animals and eggs}

GUINEA PIGS: Guinea pigs developed fever following intraperitoneal injection of citrated blood or intracerebral injection of serum taken from passage animals on their first day of fever. The incubation period was from 4 to 8 days and the febrile course was from 2 to 4 days. Young guinea pigs (200 grams body weight) showed a more prolonged febrile reaction and a shorter incubation period than adult animals. Convalescent animals remained afebrile when reinoculated with infectious passage material. Fever was the only clinical evidence of infection in guinea pigs; none of the several hundred animals used in the 90 odd passages of the agent ever appeared sick. No macroscopic or microscopic pathological changes were consistently noted in guinea pigs sacrificed at various stages of the infection. Inclusion bodies and rickettsiae were searched for in sections and smears of organs stained by Giemsa's method and other techniques; none was found.

RABBITS: The disease induced in rabbits injected with infectious guinea pig material by the intraperitoneal or intracerebral route was essentially identical with that seen in guinea pigs injected with passage material. This mild febrile illness was maintained during four serial passages in rabbits.

HAMSTERS: Adult hamsters which were inoculated intraperitoneally with blood from guinea pigs of the sixth and subsequent passages died after about 8 days. However, the disease was only irregularly reproduced in adult hamsters which were injected with blood from moribund animals of this species. Young hamsters, 40 to 60 grams body weight, proved more susceptible to the experimental infection since the agent was readily maintained by serial intracerebral passage in them. Cerebral tissue from a young hamster used for the fourth transfer titered $10^{-4}$ when tested in hamsters.

A characteristic, rapidly progressing disease developed in inoculated hamsters following an incubation period of 7 to 16 days. Some hours preceding death, these animals became abnormally irritable and showed slight ataxia. They assumed a hunched position in the darkest corner of the cage, apparently having photophobia associated occasionally with a seropurulent discharge from the eyes. Generalized tremors, but no true convulsions, were occasionally noted. The initial ataxia rapidly progressed to complete paralysis of all four extremities and death usually ensued within a few minutes. Gross and microscopic findings at autopsy were consistently normal except for areas of fresh hemorrhage in the lungs which were frequently observed and were regarded as agonal manifestations. No inclusion bodies or rickettsiae were seen in the histological sections of the central nervous system or viscera.

MICE: Infectious material injected by various routes into mice of different ages and breeds induced no obvious disease. Furthermore, serial "blind" passages were unsuccessful.

EMBRYONATED EGGS: The intravenous injection of 11-day embryonated eggs with infected serum from passage guinea pigs resulted in the death of most embryos after about 7 days of incubation at $96^{\circ} \mathrm{F}$. The agent was subsequently maintained for 23 serial transfers in embryonated eggs by the intravenous injection of suspensions of infected embryo liver diluted from $10^{-2}$ to $10^{-4}$. The embryo livers were often dark green in color, but no other abnormalities were noted. No inclusion bodies or rickettsiae were seen in stained smears of embryo viscera, yolk sac, or chorio-allantoic membranes or fluids. Embryonated eggs survived the injection of infected guinea pig plasma into the yolk sac or the chorio-allantoic sac, or onto the chorio-allantoic membrane. However, it was 
possible to demonstrate the presence of the agent in yolk sac tissue of embryos which had been injected intravenously with infected egg material and to propagate the agent thereafter by the yolk sac route. Titrations in hamsters of fresh suspensions of infected embryo liver or yolk sac usually yielded end points of $10^{-4}$.

\section{Filterability}

Plasma from febrile guinea pigs was employed in a few preliminary filtration studies on the agent. For this purpose, the plasma was diluted with an equal quantity of physiological saline solution and passed through Seitz or Corning UF filters. Virus was demonstrated to be present in the filtrate of a Corning fritted glass filter (UF) but not in that from a single Seitz pad. Materials were tested for infectivity by intravenous injection into embryonated eggs, and the presence of the virus in tissues of embryos which died was confirmed by passage to hamsters and guinea pigs.
The glass filter used in the experiment did not permit the passage of Staphylococcus albus which was added to the infected plasma.

\section{Neutralization tests}

Sera from patients convalescent from Fort Bragg fever and sera from recovered guinea pigs were tested for neutralizing antibody against the new agent. Virus for these tests consisted of undiluted guinea pig plasma or dilutions of infected chick embryo liver covering the range of $10^{-1}$ to $10^{-3}$. The technique was as follows: Equal amounts of undiluted serum to be tested and the appropriate dilution of virus were mixed and incubated for 1 hour at room temperature and then injected into groups, of two or three adult hamsters. Each animal received $0.5 \mathrm{ml}$. of the mixture intraperitoneally. The animals were observed for a period of 21 days and deaths recorded.

The results of such neutralization tests carried out on acute and convalescent sera from five cases

TABLE I

Results of neutralization tests in hamsters

\begin{tabular}{|c|c|c|c|c|c|}
\hline \multicolumn{2}{|c|}{ Sera } & \multicolumn{4}{|c|}{ Source and dilution of virus } \\
\hline \multirow{2}{*}{ Source } & \multirow{2}{*}{$\begin{array}{c}\text { Day after } \\
\text { onset }\end{array}$} & Guinea pig plasma & \multicolumn{3}{|c|}{ Chick embryo liver } \\
\hline & & Undiluted & $10^{-1}$ & $10 \rightarrow$ & $10 \rightarrow$ \\
\hline Patient $A^{* *}$ & $\begin{array}{r}5 \\
23 \\
39\end{array}$ & $\begin{array}{l}\text { D10,* D11 } \\
\text { S, S } \\
\text { S, S }\end{array}$ & $\begin{array}{l}\text { D9, D10, D11 } \\
\text { S, S, S }\end{array}$ & $\begin{array}{l}\text { D12, S, S } \\
\text { S, S, S }\end{array}$ & $\begin{array}{l}\text { D15, D16, S } \\
\text { S, S, S }\end{array}$ \\
\hline Patient B & $\begin{array}{r}4 \\
28\end{array}$ & $\begin{array}{l}\text { D12, D14 } \\
\text { S, S }\end{array}$ & $\begin{array}{l}\text { D9, D9, S } \\
\text { S, S, S }\end{array}$ & $\begin{array}{l}\text { D17, D18, S } \\
\text { D20, S, S }\end{array}$ & $\begin{array}{l}\text { D13, D13, S } \\
\text { S, S, S }\end{array}$ \\
\hline Patient C & $\begin{array}{r}4 \\
1.5\end{array}$ & $\begin{array}{l}\text { D11, D11 } \\
\text { D15, S }\end{array}$ & & & \\
\hline Patient D & $\begin{array}{r}4 \\
24\end{array}$ & $\begin{array}{l}\text { D11, D11 } \\
\text { D11, D11 }\end{array}$ & & & \\
\hline Patient E & $\begin{array}{r}4 \\
24\end{array}$ & & $\begin{array}{l}\text { D9, D9, D10 } \\
\text { D9, D9, D10 }\end{array}$ & $\begin{array}{l}\text { D13, D16, D19 } \\
\text { D10, S, S }\end{array}$ & $\begin{array}{l}\mathrm{D} 10, \mathrm{D} 10, \mathrm{D} 12 \\
\mathrm{D} 12, \mathrm{D} 13, \mathrm{D} 20\end{array}$ \\
\hline$\underset{\text { B99 }}{\text { Guinea Pig }}$ & $\begin{array}{r}0 \\
24\end{array}$ & & $\begin{array}{l}\text { D9, D9, D9 } \\
\text { S, S, S }\end{array}$ & & \\
\hline$\underset{\text { B100 }}{\text { Guinea Pig }}$ & $\begin{array}{r}0 \\
24\end{array}$ & & $\begin{array}{l}\text { D9, D9, D9 } \\
\text { D14, S, S }\end{array}$ & & \\
\hline
\end{tabular}

* D10-Death on 10th day after inoculation. S-Survived.

** The new virus was isolated from the blood of this patient. 
of Fort Bragg fever and two experimental guinea pigs are summarized in Table $I$. It is evident from the data that the convalescent sera from $\mathrm{Pa}$ tients $A$ and $B$ and from both guinea pigs contained neutralizing substances which protected the hamsters from death.

\section{Storage}

Considerable difficulty has been encountered in preserving the agent. Infectivity of blood, whole tissues, or tissues suspended in broth was lost after storage for 24 hours at $20^{\circ} \mathrm{C}$., $4^{\circ}$. C., or at $-70^{\circ} \mathrm{C}$. in sealed glass ampoules. However, viability has been maintained when 20 per cent suspensions of infected embryo tissue were pre-

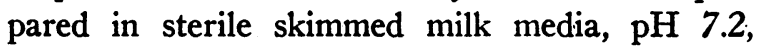
frozen rapidly in glass sealed ampoules and stored at $-70^{\circ} \mathrm{C}$. ; in one instance the agent was active after 8 months storage under these conditions. In one experiment, the infectivity of a chick embryo liver suspension diminished after storage at $-70^{\circ}$ C. for 24 hours from a titer of $10^{-4}$ to $10^{-2}$; both titrations were made in hamsters. The lability of the virus was further suggested in the tests with human subjects (see Part II). It was found that plasma taken from these patients during the febrile illness and proved to be infectious (actually whole blood was used here) by injection into other human beings, was not infectious for man after storage at $-70^{\circ} \mathrm{C}$. for 12 days. ${ }^{4}$ Fresh plasma was known to be infectious from work with hamsters.

\section{Relation to other infectious agents}

The available data are insufficient to identify this agent with any known pathogen. Sera of guinea pigs convalescent from the experimental disease failed to fix complement with the soluble antigen of lymphocytic choriomeningitis. Recovered guinea pigs were fully susceptible to infection with the Balkan Grippe strain of the rickettsia of $Q$ fever (3). Convalescent sera from three of the patients described in Part II failed to fix complement with the antigen of Rocky Mountain spotted fever; in addition, no significant titers developed in the Weil Felix reaction with OX19, OX2, and

4 This might explain the failure in 1942 of the group who investigated Fort Bragg fever to recover the agent from the blood of patients. All of the materials were stored in the frozen state for some days before injection into animals (2).
OXK. The new agent was clearly different from the rickettsia-like organism which had been previously encountered in guinea pigs used in studies on Fort Bragg fever (4). Subsequent unpublished work indicated that the infection caused by the rickettsia-like agent was enzootic in the guinea pig colony and bore no relation to Fort Bragg fever in human beings.

PART II

\section{PATHOGENICITY OF THE AGENT FOR HUMAN BEINGS 5}

In order to test the disease-producing capacity in man of the virus which had been maintained in guinea pigs and embryonated eggs, the inoculation of human subjects was next undertaken. The plan was to determine whether or not any disease could be produced by the injection of a suspension of infected egg embryo liver and, if infection occurred, to study the resistance to the new agent of individuals known to have recovered from dengue fever and from sandfly fever.

\section{METHODS}

Preliminary physical examinations were performed on all subjects; in addition, the results of $x$-ray examinations of the lungs, routine blood counts, urinalyses, and daily rectal temperatures indicated that they were, with few exceptions, in good general physical condition; all were free of intercurrent infection. Particular attention was given to examination of the skin, where long-standing blemishes might be confused later with the appearance of specific rashes. No attempt was made to isolate the patients because of the lack of epidemiological evidence for cross infection in naturally occurring Fort Bragg fever. It may be mentioned now that subsequent experience in the present studies likewise failed to suggest that the disease is contagious.

The first group of three patients were injected with a 10 per cent suspension of infected embryonated chick liver in saline. The material for this purpose was harvested from living embryos on the sixth day after intravenous injection with the 23rd egg passage, at a time when 50 per cent of the embryos had already died. This egg line had been started from the infectious serum of a guinea pig of the 80th serial passage in this host. Aerobic and anaerobic cultures of the inoculum for patients showed no growth on the usual bacteriological media. This same embryo liver emulsion was infectious at a dilution of $10^{-4}$ when titrated intracerebrally in hamsters. Mice given a

5 The human subjects used in this study were part of a group undergoing fever therapy at the Longview State Hospital in Cincinnati. 
combined intracerebral and intraperitoneal injection remained well. Guinea pigs which were also injected intraperitoneally with this inoculum developed the characteristic febrile reaction and the agent was readily transmitted to a second group of guinea pigs by inoculation of blood. It is evident that the infectious agent injected into the first group of human subjects had characteristics typical of those previously described for the virus.

The three individuals who made up the first group of subjects received $3.0 \mathrm{ml}$. intramuscularly and $0.4 \mathrm{ml}$. intracutaneously of the chick embryo liver suspension described above. Subsequent transfers of the agent to other individuals were made with blood which was drawn from the patients within 24 hours after the onset of fever. This was defibrinated, pooled, and immediately injected into the new subjects who received $5.0 \mathrm{ml}$. intramuscularly and $0.4 \mathrm{ml}$. intracutaneously.

\section{RESULTS}

A short febrile illness developed in all three of the subjects following injection with the suspension of infected chick embryo liver. The three individuals of the second group, who received pooled defibrinated blood of the first patients, developed a similar short febrile illness. Accordingly, the plan to carry out immunity studies was put into effect in the third group which consisted of two normal individuals, two persons recovered from sandfly fever, and four recovered from dengue fever. All of the patients, with one exception, in this third group developed the febrile reaction, and the majority exhibited the clinical picture of Fort Bragg fever with rash and leukopenia. The single exception was a normal subject who failed to show any fever over a 23-day period of observation. He had not been out of the state of Ohio, as far as could be determined, and his failure of response remains unexplained. The results of these studies in man are summarized in Figures 1 and 2. Figure 3 illustrates the types of rash which were seen. More detailed information concerning the various clinical features of the disease produced in man is given below. ${ }^{6}$

Incubation periods. The three individuals in the first group, inoculated with infected embryo liver suspension, came down sharply with fever on the

${ }^{6}$ One additional individual, not included in the 14 mentioned above, was injected intracutaneously with only 0.4 ml. of pooled serum from the first group of patients. He failed to develop fever during the following 20 days. Whether this person, like patient 7 , was resistant to the virus or whether larger doses of virus were required for transmission remained undecided. ninth day after inoculation. The second group developed fever from the 11 th to the 14 th day after inoculation with defibrinated blood from the first group. The third and largest group, consisting of eight individuals, had incubation periods varying from 8 to 14 days, averaging 11 . These were quite in accord with the estimate of 10 days or longer in the naturally occurring disease at Fort Bragg (2).

Fever. The temperature curves of the patients were spiking, such as occurs in the natural disease (1). Daily physical examinations failed to reveal evidence of the occurrence of intercurrent disease. The clearcut temperature elevations, ranging from $101^{\circ}$ to $105.5^{\circ} \mathrm{F}$. (rectal) and extending over a period of 1 to 6 days, average 3.2, stood out sharply from the preliminary temperature base lines. In four patients, a slight rise in temperature appeared 4 days preceding the main bout of fever. While no isolation of virus was attempted at this time, it will be noted in a subsequent paragraph that this agent circulates at least 2 days prior to the onset of the typical disease. The possibility was considered that this mild fever might represent the onset of viremia. Figures 1 and 2 show the variations in febrile response in the group of fourteen patients.

Other clinical signs and symptoms including rash. An evaluation of symptomatology in these patients was not too reliable. During the first 2 days of fever the majority complained of mild to moderate headache and aching in the back and thighs. Three individuals had mild but definite chills. There was loss of appetite, and occasional vomiting occurred. None of the patients appeared critically ill at any time, and soon after defervescence all were out of bed and had a rapid return of appetite and strength. During the course of illness, physical examination was not remarkable except for fever, splenomegaly, and rash. Three of the thirteen febrile individuals developed a definitely palpable spleen, and in two more there was questionable enlargement. A few cases developed injection of the sclerae with photophobia. There were no signs of respiratory or of meningeal involvement, and there was no significant lymphadenopathy.

No unequivocal rash was seen in any of the patients in the first two groups. However, five of the eight members of the third group developed 

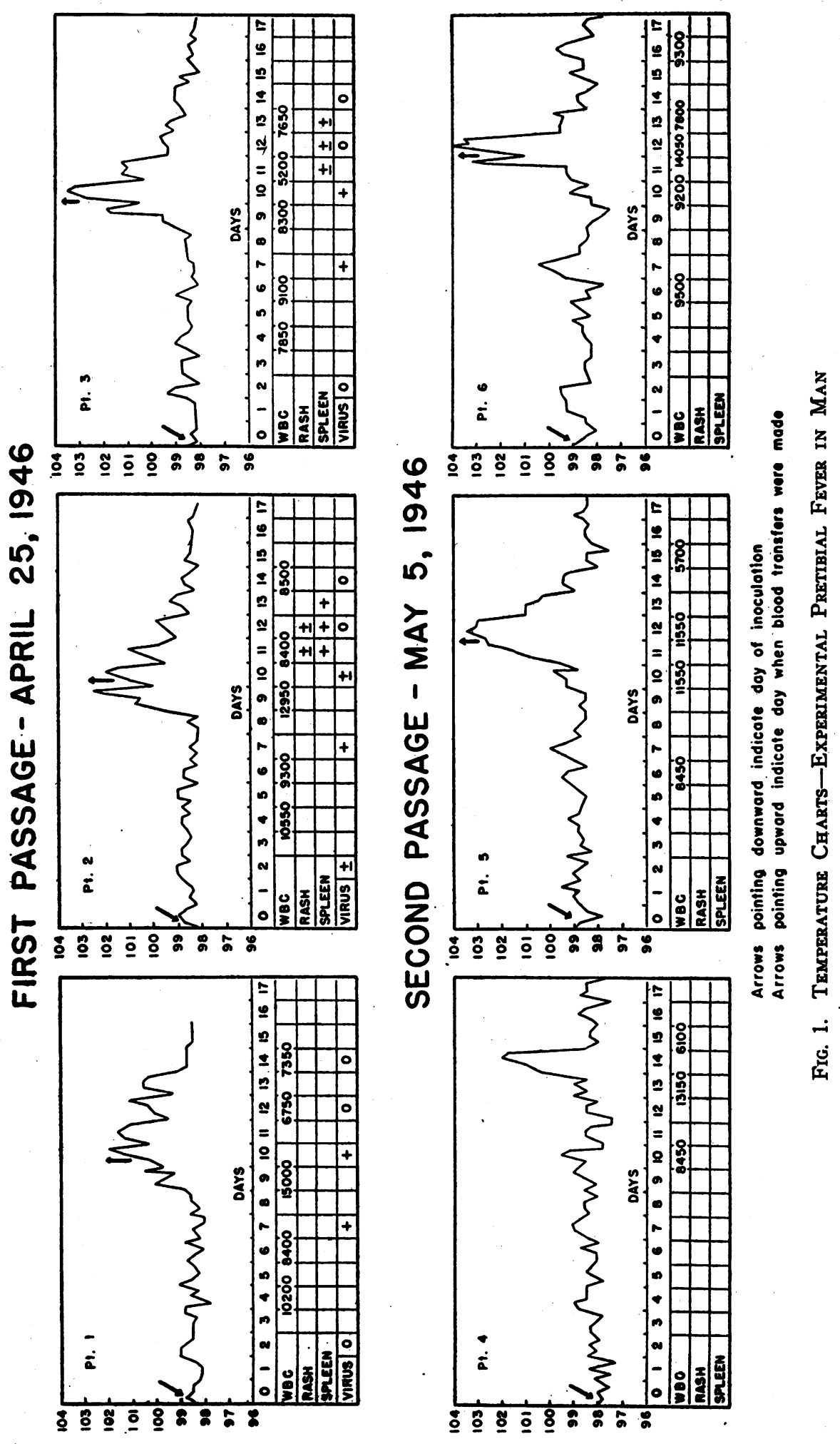


\section{THIRD PASSAGE - MAY 17, 1946}
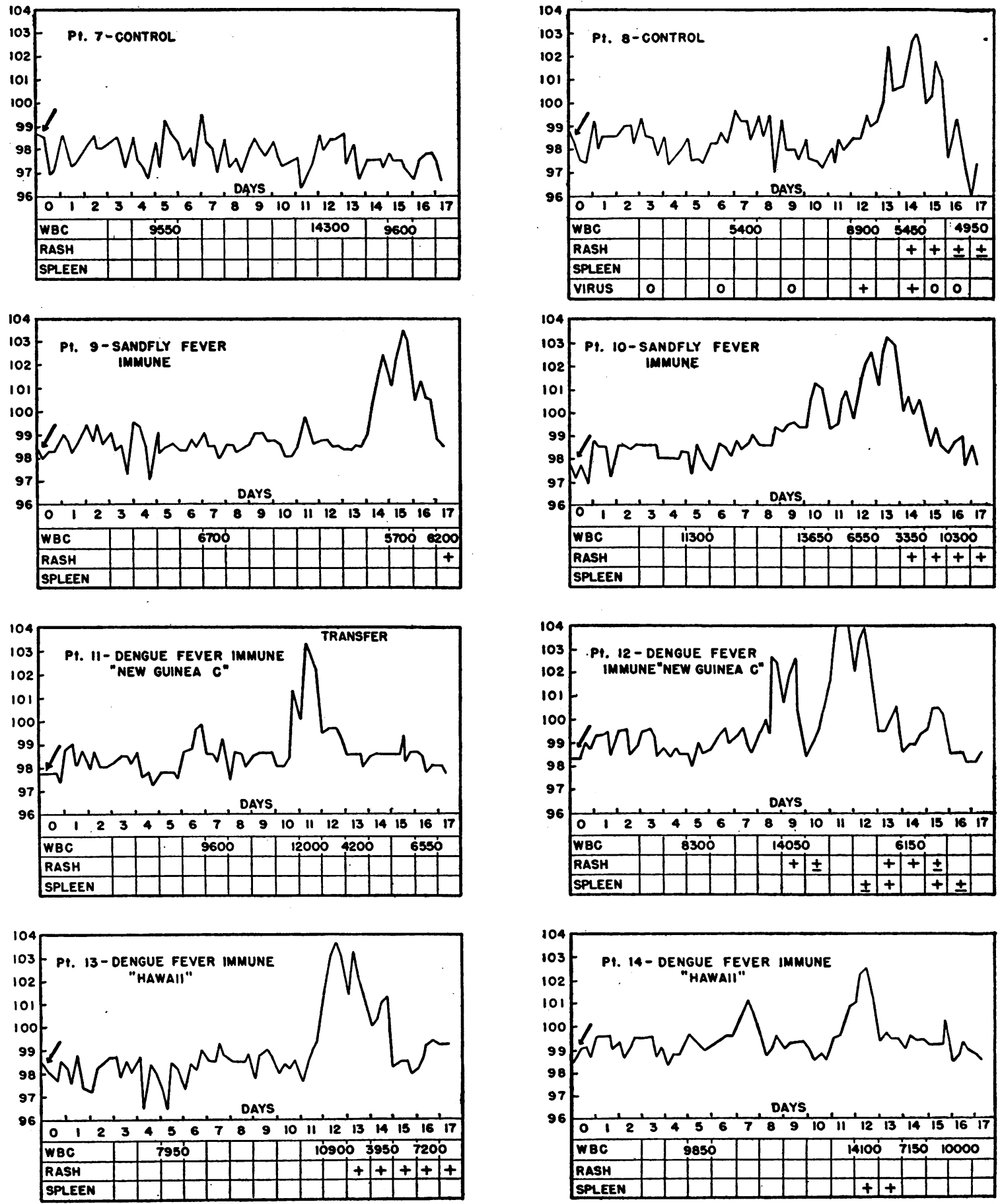

Arrows pointing downward indicate day of inoculation

Fig. 2. Temperature Charts-Experimental Pretibial Fever in Man 
TABLE II

Average total and differential leukocyte counts in the five cases with leukopenia

\begin{tabular}{l|r|r|r|r|r|r|r|r|r}
\hline \multicolumn{1}{c|}{ Days of fever } & \begin{tabular}{r|r|r|r|r|r} 
Base \\
line*
\end{tabular} & $-1 * *$ & 1 & 2 & 3 & 4 & 5 & 6 & 7 \\
\hline Total WBC & 9,531 & 11,775 & 10,950 & 11,017 & 6,500 & 5,400 & 5,940 & 6,775 & 9,400 \\
Per cent granulocytes & 62 & 73 & 79 & 79 & 64 & 61 & 55 & 50 & 65 \\
Adult forms & 57 & 67 & 73 & 74 & 52 & 56 & 43 & 47 & 61 \\
Young forms & 5 & 6 & 6 & 5 & 12 & 5 & 12 & 3 & 4 \\
Per cent lymphocytes & 36 & 26 & 20 & 19 & 34 & 38 & 43 & 47 & 27 \\
\hline
\end{tabular}

* Average of counts taken well before onset of fever; at least 2 counts per subject.

** Indicates the day before the onset of fever; subsequent numbers indicate the days after the onset of fever.

rashes of varying extent which appeared from the second to the fifth day after the onset of fever. For the most part these were limited to the anterior and lateral surfaces of the legs. The lesions were transitory and faded rapidly after the second day with evidence of residual pigmentation and small hemorrhagic areas in two of the cases.

Some of these patients were seen by Dr. Ashley A. Weech, Professor of Pediatrics, University of Cincinnati, who described their skin lesions in this manner: "The following description of the rash in experimental pretibial fever is the result of inspecting three patients, one with presumably early lesions on the fifth febrile day, another with better lesions on the third day, and the third with lesions on the seventh day. The three cases are sufficiently similar to permit one description. Lesions were present in the skin over the lower half of the tibiae in all cases; in one subject, similar lesions were present on the dorsal surface of the left forearm. The involved areas show an erythematous blush and vary in diameter from a few millimeters to a few centimeters. The borders are well defined, but the shapes are irregular. The areas are slightly elevated above the surrounding unaffected skin and on palpation feel mildly indurated. In two lesions over the tibia of one patient there was a small ecchymosis in the center. The appearance was that of fresh hemorrhage."

In one individual (patient 12), a large erythematous blush first appeared on the right shin, followed two days later by erythema and edema at the site of intracutaneous inoculation of the virus suspension. Two days after this, maculopapular erythematous lesions appeared over both shins. None of the other cases showed any reaction at the intracutaneous inoculation site. The rashes seen in the five subjects were sufficiently similar in appear- ance and distribution to the rashes described in the naturally occurring disease to leave little doubt but that the clinical picture of Fort Bragg fever had been reproduced in these human subjects.

Five of the thirteen positive cases showed a slight leukocytosis with a relative increase in granulocytes which appeared late in the incubation period and persisted for a day or so after the onset of fever (see WBC in Figures 1 and 2). Beginning about the third day of the febrile phase, a slight leukopenia with a relative lymphocytosis appeared and persisted for a few days. Further interpretation of the available data did not seem warranted. Average daily values of the leukocyte counts for these five cases are shown in Table II. The hematological findings in these individuals were similar to those in patients with Fort Bragg fever.

\section{IMMUNOLOGICAL RELATIONSHIP BETWEEN FORT BRAGG FEVER, SANDFLY FEVER, AND DENGUE FEVER}

Sabin (6) found that there are distinct immunological types of dengue virus which are sufficiently related to give rise to group specific cross immunity during the first 4 to 8 weeks, although at a later date the immunity is type-specific. Similarly in sandfly fever, one strain of virus isolated from an outbreak in Italy was completely unrelated (i.e., there was no cross immunity even during the first weeks) to two other viruses which were isolated in the Middle East and Sicily. The last two agents were identical in so far as yielding complete cross immunity even 2 years after a single experimental attack (6). The patients used in these tests (see Figure 2) were selected by $\mathrm{Dr}$. Sabin from among those he had previously inocu- 


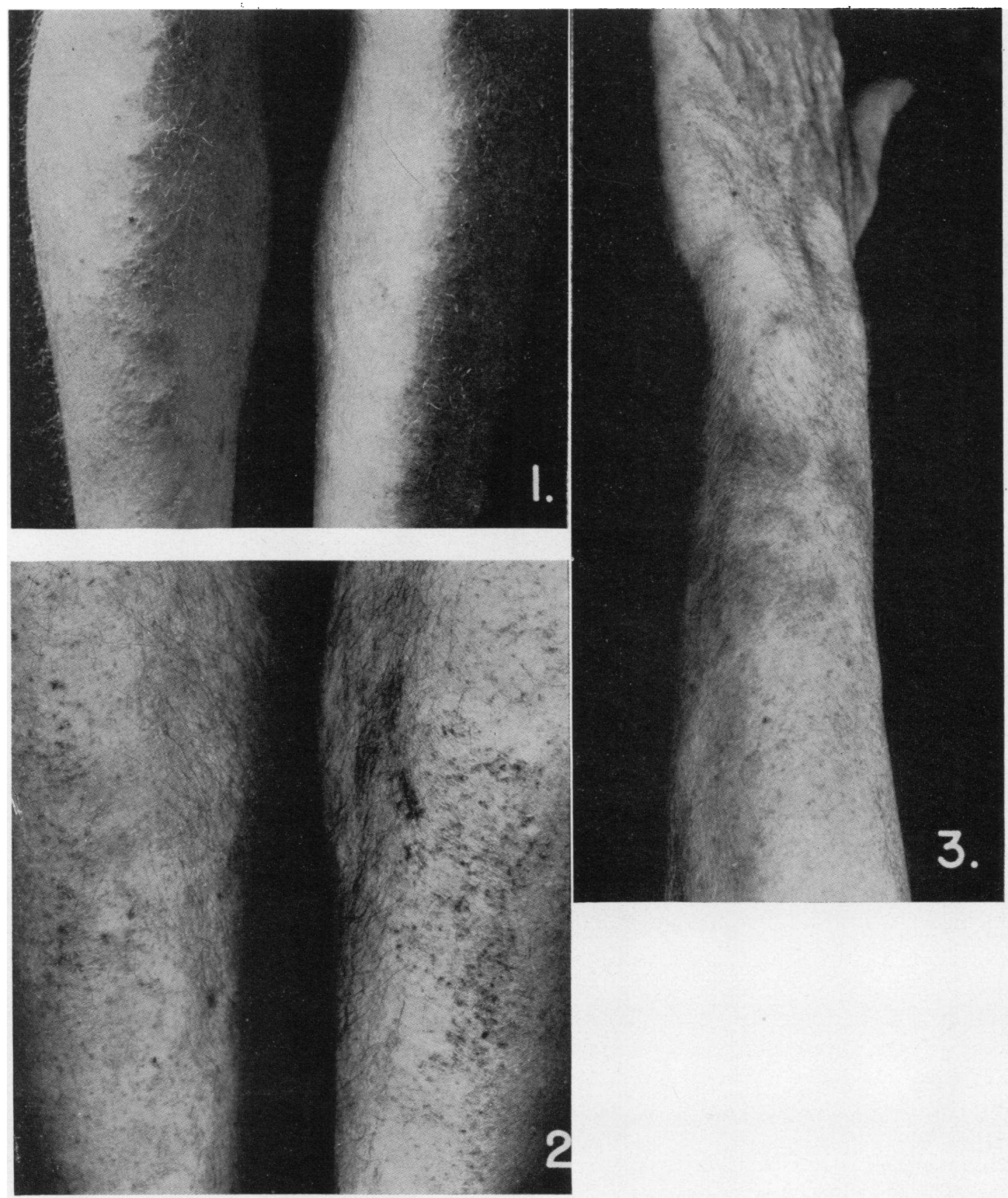

Fig. 3. Illustration of the Different Types of Rash Seen in Experinental Fort Bragi Fever in Human Beings

Figures 3(1) and 3(2) show the early and late appearance, respectively, of the anterior shin lesions in patient 10. Figure 3(3) illustrates the raised macular lesions which appeared on the forearm of patient 13. 
lated with dengue or sandfly fever viruses. Thus, patients 11 and 12, who had had typical experimental attacks of dengue following inoculation with the "New Guinea C" strain of virus 1 month before the present test, were selected since they would be expected to be immune to both "Hawaii" and "New Guinea C" strains of dengue. Patients 13 and 14, who had had experimental dengue fever following inoculation with the "Hawaii" strain of virus, 7 and 6 months, respectively, prior to the present test, would resist only an agent immunologically identical with the "Hawaii" type of virus. Similarly, patients 9 and 10 could indicate a relationship only between the new agent and the "Middle East-Sicilian" type of sandfly fever virus (5) but not with sandfly fever in general. Patient 9 had had his first attack in November, 1943 (21/2 years prior to the present test) and was immune when challenged with the homologous virus in October, 1945. Patient 10 had had his experimental attack in October 1945, or 7 months before the present test. Since all six patients developed the experimental disease produced by the new agent, it can be concluded that it possesses neither a group relationship with the known dengue viruses nor any relationship with one strain of sandfly fever virus. It may be stressed, furthermore, that neither the dengue nor the sandfly fever viruses possess the pathogenic properties of the new agent for hamsters and guinea pigs.

DETECTION OF VIRUS IN THE BLOOD OF PATIENTS

Information on the time of appearance and duration of viremia in experimentally infected human subjects was obtained in the following manner. Blood was drawn from the patients at various times during the disease, immediately defibrinated, and injected into young hamsters. In certain instances the animals received $2.0 \mathrm{ml}$. of undiluted blood intraperitoneally. In others, serial tenfold dilutions of serum were injected intracerebrally in order to determine the infective titer. Those hamsters which died between the seventh and sixteenth days were assumed to have succumbed to infection with the virus under investigation. The results of these tests in patients 1,2 , and 3, Figure 1, clearly showed that virus was present at least 48 hours before the onset of fever and was still detectable on the second day of fever, but not on the fourth day or thereafter. Patient 8 , Figure 2, had detectable virus circulating 24 hours before and 24 hours after the onset of fever, but not 4 days before nor 3 days after the onset of fever. In two instances, undiluted blood from patient 8 was lethal for hamsters but failed to kill in dilutions of 1:10 or greater. It may be concluded that the virus appeared in the blood of these patients shortly before the onset of fever and disappeared promptly; furthermore, it did not occur in large amounts.

\section{SUMMARY AND CONCLUSIONS}

An infectious agent was recovered from guinea pigs injected with blood from a soldier suffering from Fort Bragg fever in August, 1944 at Fort Bragg. The agent induced a febrile non-fatal illness in guinea pigs and rabbits and a lethal disease in hamsters. It was maintained by passage in animals or embryonated eggs, but storage even at $-70^{\circ} \mathrm{C}$. was unsatisfactory unless special precautions were taken. The agent was filterable under conditions which were adequate to retain staphylococci.

The virus, after prolonged passage in guinea pigs and embryonated eggs, was able to induce the clinical picture of Fort Bragg fever in some of the inoculated human beings, while the majority exhibited only fever for 1 to 3 days.

The new virus appears to be unrelated in its properties or immunologically to the agents of lymphocytic choriomeningitis, $Q$ fever, Rocky Mountain spotted fever, sandfly fever, and dengue fever. It does not resemble the rickettsia-like agent previously encountered in work on Fort Bragg fever and subsequently shown to be enzootic in guinea pigs.

\section{ACKNOWLEDGMENTS}

The author wishes to thank the Commission on Neurotropic Virus Diseases and particularly one member of the Commission, Dr. Albert B. Sabin, for his help in carrying out the human transmission studies. Grateful acknowledgment is made to Brig. General George C. Beach, USA, Commanding General, Army Medical Center, for granting the author detached service for the work on human subjects, to Brig. General S. Bayne-Jones, USA, and Colonel Worth B. Daniels, MC, for their interest and encouragement, and to Lt. Colonel Joseph E. Smadel, MC, for his help with the manuscript. The cooperation of Dr. Douglas Goldman, Medical Director of the Longview 
State Hospital in Cincinnati, and of Dr. E. A. Baber, Superintendent of the institution, is gratefully acknowledged.

\section{BIBLIOGRAPHY}

1. Daniels, W. B., and Grennan, H. A., Pretibial fever, an obscure disease. J. A. M. A., 1943, 122, 361.

2. Topping, N. H., Philip, C. B., and Paul, J. R., Report of the Commission for the Study of an Unidentified Disease at Fort Bragg, N. C. (Sept. 3, 1942-Sept. 11, 1942). Preliminary report submitted to the Surgeon General, U. S. Army, 15 Oct. 1942; final report 31 March 1943.
3. Commission on Acute Respiratory Diseases, Identification and characteristics of the Balkan grippe strain of Rickettsia burneti. Amer. J. Hyg., 1946, 44, 110.

4. Tatlock, H., A rickettsia-like organism recovered from guinea pigs. Proc. Soc. Exper. Biol. \& Med., 1944, 57,95 .

5. Sabin, A. B., Philip, C. B., and Paul, J. R., Phlebotomus (Pappataci or sandfly) fever, a disease of military importance, summary of existing knowledge and preliminary report of original investigations. J. A. M. A., 1944, 125, 603, 693.

6. Sabin, A. B. Personal communication. 